\title{
Amartya Sen. Premio Nobel de Economía 1998
}

\author{
Elisabetta Di Castro
}

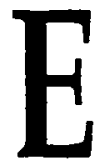

1 hindú Amartya Kumar Sen, doctor en economía por el Trinity College de Cambridge, fue distinguido con el Premio Nobel de Economía 1998 por sus estudios dedicados a la explicación y combate de uno de los fenómenos sociales más desgarradores y en el que lamentablemente su país de origen destaca a nivel mundial: la pobreza y la desigualdad.

Desde que era estudiante, Sen se preocupó por la economía del bienestar, pero fue hasta la publicación de uno de sus principales libros, Collective Choice and Social Welfare (1970), que empezó a ser reconocido internacionalmente. En este texto -que discutió entre otros, con Arrow y Rawls, y que marcó un parteaguas dentro de la teoría de elección social-, revisa los últimos estudios dedicados a las relaciones entre política social y preferencias de los ciudadanos, y plantea algunos problemas éticos fundamentales como son la conceptualización del bienestar, la racionalidad práctica y los principios de justicia. De ese mismo año es el conocido artículo "The Impossibility of a Paretian Liberal" que pone en duda uno de los principales supuestos de los economistas: la convicción de que eficiencia y libertad van unidas en las decisiones sociales. De hecho, la dificultad de reconciliar ambos principios, llevó a Sen a oponerse a la manera habitual con que la ciencia económica concibe el comportamiento humano: la hipótesis del Homo oeconomicus. Básicamente, su intento por enriquecer esa pobre concepción se volvió la piedra angular de su pensamiento filosófico.

Además de sus estudios sobre elección social, desde la década de los setentas se interesó por el problema de la pobreza, la desigualdad y la definición de principios de elección social igualitaristas. En 1981 publica Poverty and Famines en donde cuestiona el modo tradicional de entender la pobreza como falta de recursos (por ejemplo, el hambre como resultado de la escasez de alimentos); frente a ello, Sen plantea que es la estructura social 
la que también limita las "capacidades" de las personas para acceder a los bienes. En otras palabras, siguiendo con el ejemplo de los alimentos, tendríamos que la carencia de éstos no siempre se debe a catástrofes naturales, sino que muchas veces es consecuencia de la estructura de derechos que tiene la sociedad y que impiden a las personas hacerse de ellos.

En los ochentas se preocupó especialmente por los problemas éticos y metaéticos de su propuesta: evaluar el bienestar individual y colectivo por medio de las "capacidades". En esta última etapa, su crítica al utilitarismo, no sólo como doctrina económica sino también filosófica, se radicaliza. Finalmente, para Sen, el criterio de evaluación de la justicia de las instituciones sociales debe centrarse en la libertad real que tienen las personas -dentro de la estructura social que aquéllas definen-, para elegir su modo de vida. Entre sus múltiples trabajos destaca la publicación de Inequality Reexamined (1992) en donde desarrolla ampliamente sus propuestas y trabajos anteriores sobre la igualdad.

Retomemos algunas de sus principales ideas por lo que se refiere en especial al ámbito de la filosofía política. El punto de partida es su crítica al utilitarismo en la medida en que subsume la idea de justicia a la maximización del bienestar social como suma de utilidades individuales, sin tomar en cuenta las nociones básicas de libertad e igualdad. Por un lado, la suma de las utilidades es indiferente al grave problema de la distribución, ya que lo único relevante es el resultado global. Por otro lado, el propio concepto de utilidad, en tanto remite a un elemento subjetivo -ya sea como placer, como satisfacción de deseos o como elección de lo que se considera valioso-, se vuelve un elemento poco adecuado para evaluar el bienestar social. Frente a estas dificultades, el ingreso parece ser el elemento alternativo idóneo ya que es objetivo y cuantificable. Sin embargo, Sen sostiene que es un grave error creer que la posesión de bienes es determinante para el bienestar. Obviamente, hay un mínimo de bienes -como son vivienda, alimento, asistencia médica, educación, etcétera- que es crucial para el bienestar de una persona, y Sen no lo niega. Lo que hace es destacar-retomando la crítica de Marx al fetichismo de las mercancías- que las cosas no son valiosas por sí mismas, los bienes son valiosos porque son medios para ciertos fines, $y$, por ello, lo importante en el bienestar no es tanto lo que uno posea sino el tipo de vida que se tenga. En otras palabras, Sen nos propone pensar y evaluar el bienestar no por la simple posesión de bienes, sino por lo que uno logra con ellos.

En este sentido, aunque un mismo bien tiene objetivamente ciertas características, puede llevar a "funcionamientos" o "realizaciones" distintas dependiendo de la elección (o falta de elección) de las personas. Por ejemplo, en el caso de una determinada cantidad de alimento, dos personas pue- 
den obtener diversos niveles de nutrición en virtud no sólo de sus diferencias personales (como son la tasa metabólica, la edad, el sexo, la actividad que desarrollan, etcétera), sino también por diferencias sociales (si tienen acceso a servicios sanitarios, educación sobre la preparación del alimento y sus cualidades nutritivas, etcétera) e incluso por diferencias naturales (como son, por ejemplo, las condiciones climáticas). Todos estos factores se deben tomar en cuenta para poder determinar qué tanto y por qué las personas tienen diferentes "capacidades" para convertir los bienes en "funcionamien. tos" o "realizaciones".

Frente a este planteamiento, Sen da todavía un paso más. El problema de la valoración del bienestar, como hemos visto, no se agota en la satisfacción ni en la posesión de bienes, pero tampoco en el tipo de vida que se tenga, sino en que la calidad de vida que logre una persona dependa de su "capacidad" para elegirla. Las "capacidades" de una persona delimitan los "funcionamientos" o "realizaciones" que puede llevar a cabo y, por ello, marcan también el espacio en el que puede elegir. Sen propone evaluar el bienestar no sólo con base en la información sobre los "funcionamientos" o "realizaciones" alcanzados, sino también a partir del conjunto de "capacidades" de elección, lo que él denomina, la "libertad de bienestar". De esta manera, el criterio de justicia que defiende Sen es la igualdad de "capacidades", ya que éstas representan la libertad real que tiene una persona para elegir su modo de vida. Finalmente, para Sen, la evaluación y posible reforma de las instituciones sociales, lejos de centrarse en la utilidad, el ingreso o los bienes, debe dirigirse al horizonte de "libertad de bienestar", es decir, a las oportunidades reales de elección de modos de vida que una sociedad puede ofrecer a sus miembros.

El Premio Nobel de Economía a alguien que ha dedicado su vida a reintroducir la reflexión filosófica en el centro de los estudios y las discusiones económicas, es sin duda también un reconocimiento al espacio que debe recuperar la filosofía en el mundo contemporáneo. En este sentido, la comunidad filosófica tiene suficientes motivos para unirse a los festejos del merecido Premio Nobel a Amartya Sen. 